\title{
Cartographers in an uncharted terrain-the importance of going the extra mile
}

\author{
Saskia Jünger • Lukas Radbruch
}

Received: 16 October 2012 / Accepted: 23 October 2012 /Published online: 10 November 2012

(C) Springer-Verlag Berlin Heidelberg 2012

\section{Struggling for meaning in a context of medical hegemony}

Palliative care research and qualitative research methods do have in common that they are not particularly esteemed in an evidence-based medical world [9]. Their representation in specialised medical journals (including the European Journal of Pediatrics) highly committed to biomedical research, clinical studies and randomised controlled trials isto say the least - modest. It must therefore be honoured if a research group has the courage to introduce these topics and promote another medical and research paradigm, as Bergstraesser et al. do with their paper on the needs of Swiss health-care professionals in the palliative care of children and adolescents [1].

The definition of palliative care asks for a "holistic approach" in order to improve the quality of life of patients and families - and herein encompasses values and attitudes toward life and death. This means that palliative care researchers often need to rely on people's narratives - the perspectives of stakeholders, patients, their families, or professional caregivers. The definition of evidence-based medicine "recognizes that many aspects of health care depend on individual factors such as quality- and value-of-life judgements, which are only partially subject to quantitative

S. Jünger $(\bowtie) \cdot$ L. Radbruch

Department of Palliative Medicine, University Hospital Bonn, Bonn, Germany

e-mail: saskia.juenger@ukb.uni-bonn.de

L. Radbruch

Centre for Palliative Medicine,

Malteser Hospital Bonn/Rhein Sieg,

Bonn, Germany scientific methods" such as measuring or counting, or to say it in Albert Einstein's words, "Not everything that can be counted counts; and not everything that counts can be counted". The study of Bergstraesser et al. does justice to this claim by acknowledging the importance of exploring health-care professionals' knowledge, attitudes and needs in order to inform a targeted planning of paediatric palliative care services and by choosing the appropriate qualitative research methods to gain a profound understanding of these issues.

\section{Cartographers in an uncharted terrain}

As a palliative care researcher, one often feels like a cartographer in an uncharted terrain-especially when dedicating one's scientific efforts to health service research in palliative careand even more in paediatric palliative care. One "cartographic challenge" is the definition of the borders of palliative care; another is the question what terrain is inside these borders, and what is beyond its scope. Key questions in this context concern the roles and responsibilities of palliative care in relation to other disciplines and the roles and responsibilities of "generalist" vs. "specialist" palliative care.

In addition, there is an ongoing and continuously evolving scientific discussion on the patient groups in need of palliative care and the conditions potentially requiring palliative care. In paediatric palliative care, there is a broad spectrum of lifelimiting conditions requiring palliative care at a certain point during the disease trajectory. For example, Knapp et al. identified more than 70 potentially life-limiting diagnoses (ICD-9 codes; differentiation into decimals not counted) [6].

\footnotetext{
${ }^{1}$ http://en.wikipedia.org/wiki/Evidence-based_medicine
} 
In an attempt to survey the palliative care landscape, to allow for comparison between countries and to establish international standards, there are various international mapping initiatives in the field of palliative care in Europe [4] or worldwide $[7,10]$ and a more recent initiative for the mapping of palliative care services for children and adolescents. ${ }^{2}$

\section{Going one step beyond}

The number of palliative care publications is continuously increasing, and health service research in palliative care has gained more and more importance over the past years. However, the transfer of research findings from one country to another is not always possible due to differences in health care systems and culture. Target-specific needs assessment research therefore can be essential to promote palliative care development in a certain region or country.

If new (qualitative) studies want to really add to the scientific knowledge in this area-if we do not want to end up with a mere description of the results and a comparison with findings of previous studies - we need to go the extra mile: we need to be aware of our responsibility to reflect the findings of our studies and their implications for the particular health care system and the wider societal background. Contextual aspects such as population density, geography, distances between service providers and the patients' homes, service provision in rural and remote areas, reimbursement issues, and cultural and historical aspects are crucial for a sound planning of (paediatric) palliative care services.

Here, the paper on the needs of Swiss health-care professionals in the palliative care of children and adolescents might benefit from going one step beyond and reflecting the study results against the palliative care development in Switzerland. Interestingly, in international rankings on palliative care development, Switzerland is presented with different faces. On the other hand, Switzerland is one of the few countries that have a national palliative care policy in place [3]; in the international mapping of palliative care development, it is grouped in the highest level, with advanced integration into mainstream service provision [7]. On the other hand, Switzerland only ranks 19th in the overall ranking of the "Quality of Death Index" [3]. Notably, it ranks first in the "Basic End-of-Life Care Environment" but 30th (of 40 countries) in the Quality of End-of-Life Care, and the public awareness of end-of-life care was described as low despite a national palliative care strategy! What do

\footnotetext{
$\overline{2}$ http://www.eapcnet.eu/Themes/Specificgroups/Childrenandyoung people/MappingofpaediatricPCservices.aspx
}

these inconsistent findings mean for the development of specialised paediatric palliative care in Switzerland?

Transition from paediatric to adult palliative care services was reported to be one of the key findings in terms of practical implications of the study [1]. This is a crucial issue in paediatric palliative care. For readers both inside and outside Switzerland, it would be very interesting to hear more details about these practical implications. For example, how is reimbursement regulated in Switzerland for children and adult health care? What would be needed in terms of infrastructure, expertise and consultation, education and training, interdisciplinary collaboration, and coordination of services in order to address this challenge?

Also, the authors found that home-based respite care was preferred above hospice-based respite care by parents, whereas health-care professionals mentioned possible advantages of such hospice-based respite care. Here, a reflection on possible reasons for the parents' reservations and suggestions on how to address these would be helpful. A German study found that parents of children with a lifelimiting disease associated the term "hospice" with withdrawal of medical therapy and the terminal phase of life since they were not aware of children's inpatient hospices offering short-term medical and respite care [5]. However, often, these reservations could be addressed by providing information and by ensuring a respectful relationship with child and parents, taking account of the child's individual needs and respecting the parents' expertise in caring for their child.

\section{Going the extra mile}

The study by Bergstraesser et al. [1] is highly informative for the specific situation in Switzerland since it highlights challenges, shortcomings and needs in promoting paediatric palliative care provision. Its focus on a broad range of health-care professionals not specialised in paediatric palliative care - but willing to commit themselves to the care for children with complex chronic/life-limiting conditions-is in line with an increasing emphasis on strengthening generalists (e.g., general practitioners and community nurses) in providing basic palliative care by supporting them with specific information, supervision and consultation by specialists.

One challenge inherent in qualitative research based on narratives is that the results are at risk of appearing hazy compared to quantitative outcomes. In order to minimise this risk, it is of utmost importance to apply the standards of good scientific practice to qualitative research to justify the rationale for the methods, to ensure adequate validity and reliability, to describe the results transparently and to substantiate the conclusions. 
Sound qualitative research has the potential of informing palliative care policy and guidelines for service provision. For example, the End of Life Care Strategy (UK) and the Clinical Practice Guidelines for Quality Palliative Care (USA) were both informed by scientific evidence partly based on studies using qualitative methods [2, 8]. These examples show that qualitative methodology has the potential to provide an important contribution to local, regional and national planning of (paediatric) palliative care services. Therefore, we would like to encourage paediatric palliative care researchers to continue addressing challenges in service provision - using both qualitative and quantitative methods - and to be high-quality cartographers in an (partly) uncharted terrain by daring to go the extra mile.

Conflict of interest The authors declare that they have no conflict of interest.

\section{References}

1. Bergstraesser E, Inglin S, Abbruzzese R, Marfurt-Russenberger K, Hosek M, Hornung R (2012) The needs of professionals in the palliative care of children and adolescents. Eur J Pediatr doi:10.1007/s00431-012-1880-8
2. Department of Health (2008) End of Life Care Strategy. Promoting high quality care for all adults at the end of life. http://www.dh. gov.uk/prod_consum_dh/groups/dh_digitalassets/@dh/@en/ documents/digitalasset/dh_086345.pdf. Accessed 12 Oct 2012

3. Economist Intelligence Unit (2010) The quality of death. Ranking end-of-life care across the world. A report from the Economist Intelligence Unit. Lien Foundation, London

4. European Association for Palliative Care (2007) The EAPC atlas of palliative care in Europe. http://www.eapcnet.org/Policy/ EAPC.Atlas.htm. Accessed 21 Jan 2008

5. Hahnen M, Jünger S, Grumbach-Wendt M, Reichling S, Radbruch L (2009) Die palliativversorgung von kindern und jugendlichen in Nordrhein-Westfalen aus der sicht der eltern. Z Palliativmed 10:199-205

6. Knapp CA, Madden VL, Curtis CM, Sloyer PJ, Huang IC, Thompson LA, Shenkman EA (2008) Partners in care: together for kids: Florida's model of pediatric palliative care. J Palliat Med 11 (9):1212-1220

7. Lynch T, Clark D, Connor SR (2011) Mapping levels of palliative care development: a global update 2011. Worldwide Palliative Care Alliance, London

8. National Consensus Project (2009) Clinical Practice Guidelines for Quality Palliative Care, 2nd edn. National Consensus Project for Quality Palliative Care, Pittsburgh

9. Payne SA, Turner JM (2008) Research methodologies in palliative care: a bibliometric analysis. Palliat Med 22(4):336-342. doi:10.1177/0269216308090072

10. Wright M, Wood J, Lynch T, Clark D (2008) Mapping levels of palliative care development: a global view. J Pain Symptom Manag 35(5):469-485. doi:10.1016/j.jpainsymman.2007.06.006 